\title{
Creep of radiation cross linked HDPE at elevated temperature Martin Reznicek ${ }^{1, a}$, David Manas ${ }^{1, b}$, Michal Stanek ${ }^{1, c}$, Martin Ovsik $^{1, d}$, Martin Bednarik ${ }^{1, \mathrm{e}}$, Adam Skrobak ${ }^{1, \mathrm{f}}$, Ales Mizera ${ }^{1, \mathrm{~g}}$ \\ ${ }^{1}$ Tomas Bata University in Zlin, nam. T. G. Masaryka 5555, 76001 Zlin, Czech Republic (phone: +420576035062) \\ amreznicek@ft.utb.cz, bdmanas@ft.utb.cz, ${ }^{\mathrm{c}}$ stanek@ft.utb.cz, dovsik@ft.utb.cz, embednarik@ft.utb.cz, ${ }^{\mathrm{f}}$ skrobak@ft.utb.cz, ${ }^{9}$ mizera@ft.utb.cz
}

Keywords: creep, high temperature, HDPE, radiation cross linking, polymer

\begin{abstract}
This article studies creep of a radiation cross linked HDPE polymer material. It describes a process of production of test samples, which are then radiation cross linked in six doses of radiation. These samples are tested for creep resistance at elevated temperatures on a machine of custom design that will provide sufficient information about a suitable use for the material and to find an optimal dose to achieve minimal stretching. [1-3]
\end{abstract}

\section{Introduction}

The aim of designers of polymer products is to maximize the utilization of the material properties of the selected type of a polymeric material. Often the chosen construction material has to be replaced by a high-tech material, which leads to a significant increase in the material costs, thus increasing the cost of the whole product. One of the possible ways to reduce these costs is to use a construction material which is radiation cross linked. Radiation cross linking gives the material properties similar to a high-tech material but at only a fraction of the price.

The effect of radiation cross linking has been demonstrated mainly in the use of the material at elevated temperatures, where a cross linked spatial network with increased resistance to failure is formed. [4, 5] Materials that are subject to long-term load deformation by time and load. For this reason the creep test is performed. The test specimen is loaded with either a constant load or a constant force and its deformation is monitored over time. In this type of test, temperature dependence was observed on the rate of deformation, therefore a creep test at elevated temperature is chosen. $[1,2]$



Fig. 1. Creep test 


\section{Method}

HDPE material from DOW Company was chosen for this creep test. It is marketed under a codename E25050E. The shape of the samples was chosen by an EN 527 standard - small test samples type 1BA.

The test samples were molded on an injection molding machine Arburg Allrounder 170U with process conditions

Table 1. Process parameters

\begin{tabular}{|l|l|}
\hline Track of dosage & $48 \mathrm{~mm}$ \\
\hline Mold temperature & $40^{\circ} \mathrm{C}$ \\
\hline Input range temperature & $180^{\circ} \mathrm{C}$ \\
\hline Transition zone temp. & $190^{\circ} \mathrm{C}$ \\
\hline Output range temperature & $195^{\circ} \mathrm{C}$ \\
\hline Nozzle temperature & $200^{\circ} \mathrm{C}$ \\
\hline Injection speed & $40 \mathrm{~mm} / \mathrm{s}$ \\
\hline Switching point & $15 \mathrm{~mm}$ \\
\hline Lockout & $60 \mathrm{MPa}$ \\
\hline Cooling time & $35 \mathrm{~s}$ \\
\hline
\end{tabular}

The molded test samples were radiation cross linked in BGS Company in Germany with doses of $33 \mathrm{kGy}, 66 \mathrm{kGy}, 99 \mathrm{kGy}, 132 \mathrm{kGy}, 165 \mathrm{kGy}$, and 198kGy.

Creep test was performed on a custom made machine. This device allows to clamp up to four test samples and to load them with up to $1000 \mathrm{~N}$ in temperature range from $40^{\circ} \mathrm{C}$ to $250{ }^{\circ} \mathrm{C}$. The selected test samples were loaded with a constant force of $80 \mathrm{~N}$ during the test. Chamber temperature was $80^{\circ} \mathrm{C} \pm 2{ }^{\circ} \mathrm{C}$, which was regularly checked. Length of the test here was due to the material used, the load and temperature set to 24 hours.
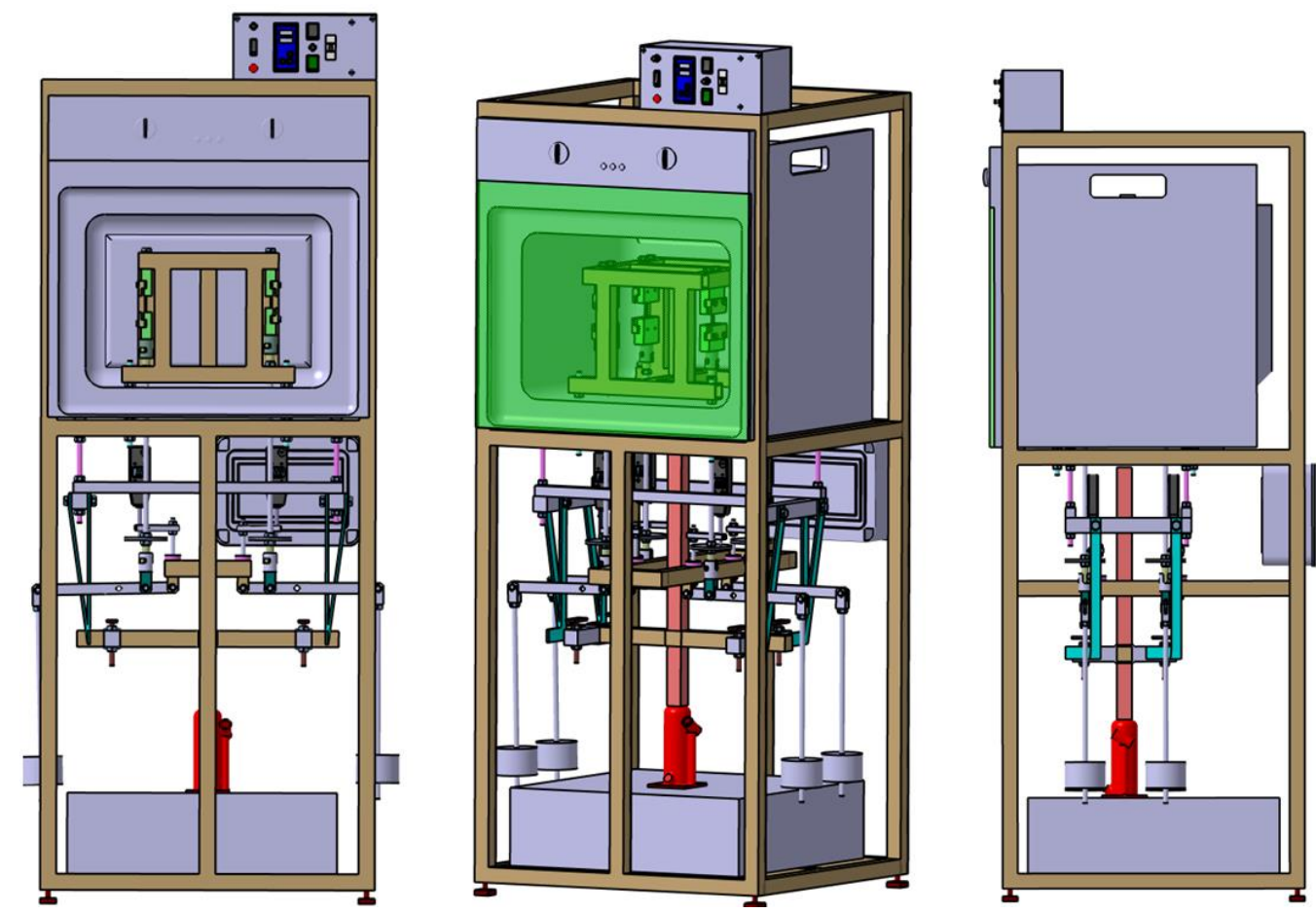

Fig. 2. Creep measuring machine

Each set was measured three times and a total of 12 measurements were obtained, which were then statistically analyzed. 


\section{Results}

The results of individual measurements for all doses were plotted and checked for bias and suspicious values. For better clarity, the control is displayed every four hours during the measurement.



Fig. 3. Check of bias and suspicious values for $0 \mathrm{kGy}$

As we can see in Fig. 3 the measurement there are is no bias or suspicious values. This check has been done for all doses of radiation with negative results. After this inspection graphs of the results of individual values were constructed. The result for example dose of $0 \mathrm{kGy}$ can be seen in Fig. 4 .

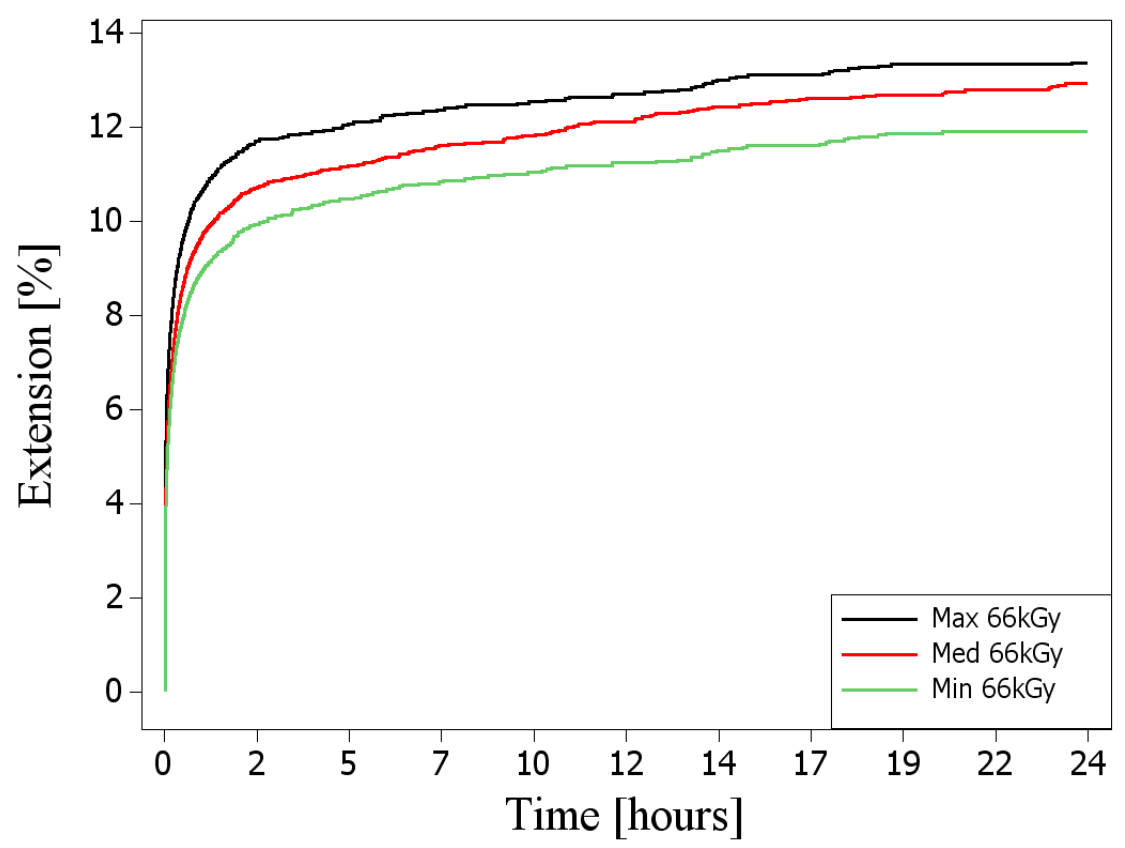

Fig. 4. Example of the results for dose of $66 \mathrm{kGy}$

Using the graph displaying the maximum, median and minimum dose for 66kGy may provide evidence that the measurements do not significantly deviate and can therefore be used for further data processing. For the sake of clarity only the median value are displayed in the next graph because of the small number of measurements. 


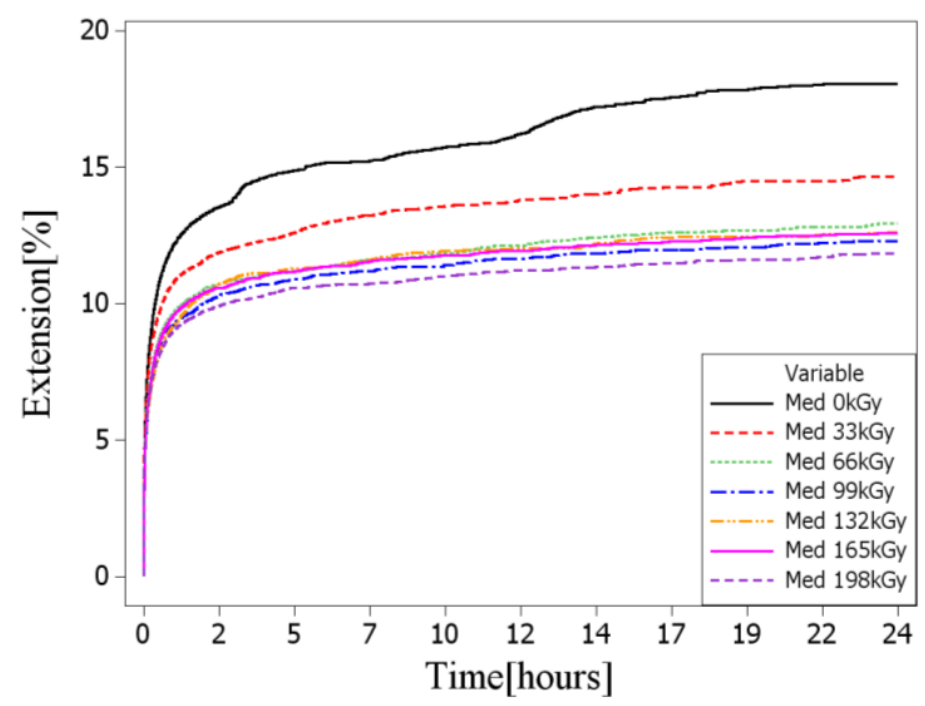

Fig. 5. Elongation of a radiation cross linked HDPE

As shown by the median value plotted in Fig. 5, the differences in elongation of radiation cross linked HDPE caused by the dose of radiation cross linking can be seen. The smallest dose of radiation $33 \mathrm{kGy}$ decreased the relative elongation by 5\% during 24 hours. A further increase of the dose has further improved the creep properties of $3 \%$, which has not significantly increased with higher dose.

\section{Summary}

This article focused on the study of the creep behavior of radiation cross-linked HDPE material at elevated temperatures. Manufactures small test samples were cross linked with seven doses radiation $(0 \mathrm{kGy}, 33 \mathrm{~kg}-198 \mathrm{kGy})$ and tested for creep at $80^{\circ} \mathrm{C}$ with a repeatability of 12 samples. Resulting graph shows the effects of cross linking, which can have a decisive influence on the choice of material and the dose by which it can be modified. Based on measured data, the best ratio of price and quality of radiation to cross-link the material was a dose of $66 \mathrm{kGy}$. Higher doses have no usable value and would only make the product more expensive.

\section{Acknowledgment}

This paper is supported by the internal grant of TBU in Zlin No. IGA/FT/2014/016 funded from the resources of specific university research and by the European Regional Development Fund under the project CEBIA-Tech No. CZ.1.05/2.1.00/03.0089 and Technology Agency of the Czech Republic as a part of the project called TA03010724 AV and EV LED luminaire with a higher degree of protection.

\section{References}

[1] M.; Manas, M. \& Manas, D. (2009). Mold Cavity Roughness vs. Flow of Polymer, Novel Trends in Rheology III, AIP, ISSN 0094-243X, pp.75-85

[2] Stanek, M.; Manas, M.; Manas, D. \& Sanda, S. (2009). Influence of Surface Roughness on Fluidity of Thermoplastics Materials, Chemicke listy, Volume 103, ISSN 0009-2770, p.91-95

[3] Gutt, G.; Gutt, S.; Severin, T. - L. \& Vasilache, V. (2010). Research on the Spatial Distibution of Mechanical Characteristics in a Cadmium Telluride Crystal, Annals of DAAAM for 2010 \& Proceedings of the 21 st International DAAAM Symposium, 20-23rd October 2010, Zadar, Croatia, ISSN 1726-9679, ISBN 978-3901509-73-5, Katalinic, B. (Ed.), pp. 0993-0994, Published by DAAAM International Vienna, Vienna

[4] Manas, D., Stanek, M., Manas, M., Pata V., Javorik, J., "Influence of Mechanical Properties on Wear of Heavily Stressed Rubber Parts”, KGK - Kautschuk Gummi Kunststoffe, 62. Jahrgang, 2009, p.240-245.

[5] M. Ovsik, D. Manas, M. Manas, M. Stanek, S. Sanda, K. Kyas:“ Microhardness of PA6 Influenced by Beta Low Irradiation Doses“, International Journal of Mathematics and Computers in Simulation, Volume 6, Issue 6, 2012, p. 575-583, ISSN 1998-0159. 